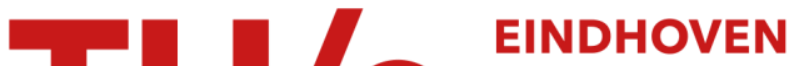 UNIVERSITY OF TECHNOLOGY
}

\section{Growth kinetics of cobalt carbonate nanoparticles revealed by liquid-phase Scanning transmission electron microscopy}

\section{Citation for published version (APA):}

Su, H., Mehdi, B. L., Patterson, J. P., Sommerdijk, N. A. J. M., Browning, N. D., \& Friedrich, H. (2019). Growth kinetics of cobalt carbonate nanoparticles revealed by liquid-phase Scanning transmission electron microscopy. Journal of Physical Chemistry C, 123(41), 25448-25455. https://doi.org/10.1021/acs.jpcc.9b06078

DOI:

10.1021/acs.jpcc.9b06078

Document status and date:

Published: 17/10/2019

\section{Document Version:}

Publisher's PDF, also known as Version of Record (includes final page, issue and volume numbers)

\section{Please check the document version of this publication:}

- A submitted manuscript is the version of the article upon submission and before peer-review. There can be important differences between the submitted version and the official published version of record. People interested in the research are advised to contact the author for the final version of the publication, or visit the $\mathrm{DOI}$ to the publisher's website.

- The final author version and the galley proof are versions of the publication after peer review.

- The final published version features the final layout of the paper including the volume, issue and page numbers.

Link to publication

\section{General rights}

Copyright and moral rights for the publications made accessible in the public portal are retained by the authors and/or other copyright owners and it is a condition of accessing publications that users recognise and abide by the legal requirements associated with these rights.

- Users may download and print one copy of any publication from the public portal for the purpose of private study or research.

- You may not further distribute the material or use it for any profit-making activity or commercial gain

- You may freely distribute the URL identifying the publication in the public portal.

If the publication is distributed under the terms of Article 25fa of the Dutch Copyright Act, indicated by the "Taverne" license above, please follow below link for the End User Agreement:

www.tue.nl/taverne

Take down policy

If you believe that this document breaches copyright please contact us at:

openaccess@tue.nl

providing details and we will investigate your claim. 


\title{
Growth Kinetics of Cobalt Carbonate Nanoparticles Revealed by Liquid-Phase Scanning Transmission Electron Microscopy
}

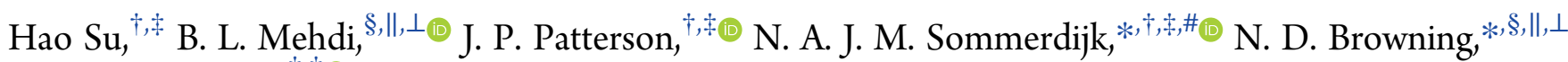 \\ and H. Friedrich $*,+\ddagger 0$
}

\begin{abstract}
${ }^{\dagger}$ Laboratory of Materials and Interface Chemistry and Centre for Multiscale Electron Microscopy Department of Chemical Engineering and Chemistry and ${ }^{+}$Institute for Complex Molecular Systems, Eindhoven University of Technology, P.O. Box 513, $5600 \mathrm{MB}$ Eindhoven, The Netherlands

${ }^{\S}$ Physical and Computational Science Directorate, PNNL, Richland, Washington 99354, United States

"Department of Mechanical, Materials and Aerospace Engineering and Department of Physics, University of Liverpool, Liverpool L69 3GQ U.K.
\end{abstract}

\section{Supporting Information}

ABSTRACT: Amorphous precursor phases have been observed in many crystallization processes in aqueous solution, yet their growth kinetics are not fully understood because of their often transient and unstable nature. In this work, we try to close this knowledge gap by employing liquid-phase scanning transmission electron microscopy (LPSTEM) to study the growth kinetics using amorphous cobalt carbonate $\left(\mathrm{CoCO}_{3}\right)$ as a model system. Using simultaneous acquisition of bright-field and annular dark-field LPSTEM images, we observe that the volume of the amorphous $\mathrm{CoCO}_{3}$ nanoparticles grows linearly with time. By quantifying and extrapolating electron beam effects to zero dose, the growth rate at native solution conditions is obtained. From the observed linear volume growth and the observation of $10 \mathrm{~nm}$-sized nanoparticles by cryotransmission electron microscopy (cryoTEM), we conclude that growth of amorphous $\mathrm{CoCO}_{3}$ nanoparticles proceeds through assembly of the $10 \mathrm{~nm}$ primary particles. Our observations not only provide unique insights into the nanoscale growth kinetics of an amorphous phase in aqueous solution that may open the way to improved synthesis protocols of the Co catalyst for Fischer-Tropsch synthesis.

\section{INTRODUCTION}

The formation of, often metastable, amorphous intermediates occurs in many crystallization processes in aqueous solution. ${ }^{1}$ It has been reported that amorphous phases exist in many mineral systems, including calcium carbonate ${ }^{2-4}$ and calcium phosphate. $^{5-7}$ On several accounts, these amorphous phases are suggested to form via aggregation of nanometer-sized prenucleation species or primary particles. ${ }^{2,7,8}$ Understanding the growth kinetics of these amorphous precursor phases is essential to gain a fundamental understanding of the entire mineralization process. However, so far, the growth of amorphous phases through particle assembly is mostly studied in static, using ex situ measurements. ${ }^{5,9,10}$ This is in contrast to the study of crystallization by oriented attachment, where in situ high resolution observations gave unprecedented insights into the kinetics of these processes. ${ }^{11,12}$

Liquid-phase (scanning) transmission electron microscopy [LP (S)TEM] provides unique advantages for studying the growth kinetics of nanomaterials, by allowing direct observation of the dynamics of nanoparticle nucleation and growth in solution. ${ }^{13,14}$ The method has been applied for the observation of nucleation and growth of nanostructures in different solvents, ${ }^{14}$ and holds great promise as a powerful tool to study nanoparticle growth kinetics in situ. However, amorphous mineral precursors are usually transient and beam sensitive, ${ }^{15}$ and it has been reported that the electron beam can change the $\mathrm{pH}$ value of solutions. ${ }^{16,17}$ This can affect the kinetics of the mineral growth and therefore makes it difficult to observe the native growth kinetics via LP (S)TEM. Besides, to fully understand the growth kinetics of the amorphous particles, it is important to measure their growth rate in all three dimensions, which is difficult by using conventional LP(S)TEM, which records the image series containing only the two-dimensional (2D) morphology of objects.

Amorphous cobalt carbonate $\left(\mathrm{CoCO}_{3}\right)$ nanoparticles have been reported as a very stable amorphous mineral at ambient temperature, ${ }^{18}$ making it a perfect model system to study the growth kinetics of the amorphous phase. Moreover, $\mathrm{CoCO}_{3}$ nanoparticles are an important intermediary precursor in the

Received: July 1, 2019

Revised: September 23, 2019

Published: September 24, 2019 


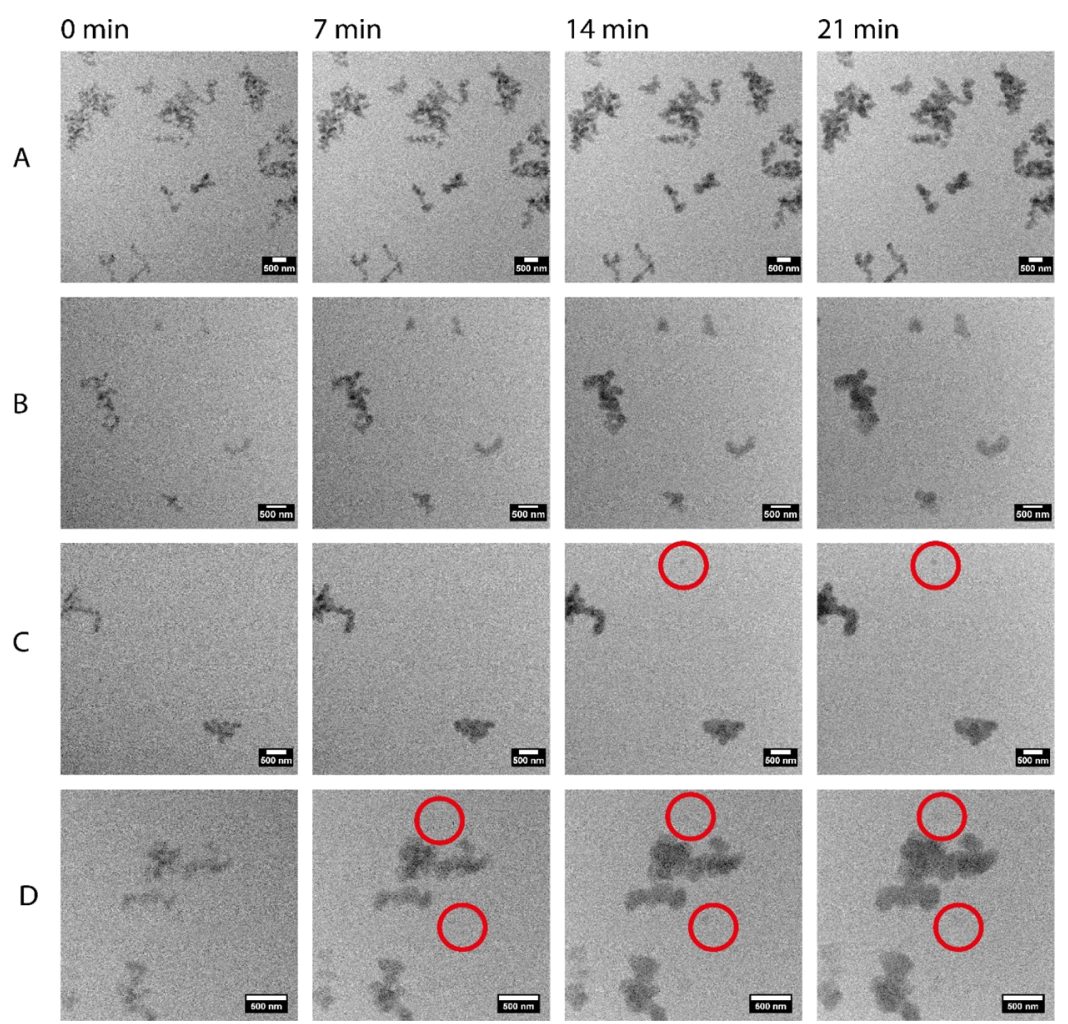

Figure 1. BF STEM images from four different $\mathrm{CoCO}_{3}$ growth experiments, where the micrographs in columns $1-4$ were taken at $0,7,14$, and 21 min after inserting the holder into a transmission electron microscope. Rows (a-d) refer to growth experiments at electron flux of (a) 7.8, (b) 9.6, (c) 15.6 , and (d) $30 \mathrm{e}^{-} / \mathrm{nm}^{2} / \mathrm{s}$. The red circle indicates the new nucleation events. Movies at $7.8 \mathrm{e}^{-} / \mathrm{nm}^{2} / \mathrm{s}$ are shown as an example in Video S1 (BF) and Video S2 (ADF).

synthesis of Co nanoparticles that are used in catalysis, for example, in the Fischer-Tropsch process. ${ }^{19-21}$ The size and morphology of the formed $\mathrm{CoCO}_{3}$ have a high impact on the final morphology and, hence, the catalytic performance of the final Co nanoparticles. ${ }^{20,22}$ Understanding the growth kinetics of $\mathrm{CoCO}_{3}$ nanoparticles could therefore help optimize the performance of the final Co catalyst in terms of the catalytic activity and long-chain hydrocarbon selectivity.

In this work, we directly observe the dynamics of the nucleation and growth of $\mathrm{CoCO}_{3}$ nanoparticles in LP-STEM. By using bright-field (BF) and annular dark-field (ADF) STEM simultaneously, ${ }^{23}$ we are able to visualize the threedimensional (3D) volume growth kinetics of the amorphous nanoparticles. By systematically changing the electron flux and performing reactions at different concentrations of $\mathrm{Co}^{2+}$ and $\mathrm{CO}_{3}{ }^{2-}$, we are able to extrapolate the growth rate to zero electron dose, thereby obtaining unique artifact-free information on the growth dynamics of these particles in solution. We observe that the volume of $\mathrm{CoCO}_{3}$ nanoparticles increases linearly with time, revealing that their growth cannot be driven by monomer-by-monomer addition of ions. Cryotransmission electron microscopy (cryoTEM) and dynamic light scattering (DLS) reveal indeed that volume growth occurs through aggregation of $\sim 10 \mathrm{~nm}$-sized primary particles in solution.

\section{RESULTS AND DISCUSSION}

Observation of Particle Growth in 3D. The $\mathrm{CoCO}_{3}$ nanoparticles were synthesized through mixing a drop of aqueous $120 \mathrm{mM}\left(\mathrm{NH}_{4}\right)_{2} \mathrm{CO}_{3}$ solution $(500 \mathrm{~nL})$ and a drop of $120 \mathrm{mM} \mathrm{Co}\left(\mathrm{NO}_{3}\right)_{2}$ solution $(500 \mathrm{~nL})$ on the LP STEM chip. The observation started after approximately $15 \mathrm{~min}$ after mixing the reagents and assembly of the cell. LPSTEM showed that aggregated nanoparticles were present from the beginning of the observations (Figure 1). The complete absence of nanoparticle motion throughout the viewing area suggests that they are adhered to the $\mathrm{SiN}$ window which is beneficial for quantitative analysis. Combined ex situ electron energy loss spectroscopy (EELS) and electron diffraction of the dry particles, after the experiment, confirmed that they consisted of amorphous $\mathrm{CoCO}_{3}$ (Figures 2, S1). Because no ionic bonding or covalent bonding was found from EELS data, it can be concluded that there is no chemical reaction between $\mathrm{CoCO}_{3}$ nanoparticles and the $\mathrm{SiN}$ window. Therefore, we conclude that the adhesion of the nanoparticles is due to van der Waals force, which is widely observed in the nanoparticle-substrate system. $^{24,25}$

The nanoparticles grew in size from $\sim 50 \mathrm{~nm}$ (see also Figure S1b) to $100-300 \mathrm{~nm}$ depending on the electron flux used (Figure 1). Faster growth rates were observed at higher electron flux, suggesting that the electron beam effects increased the supersaturation of the solution. The appearance of new particles was only observed at an electron flux above $15.6 \mathrm{e}^{-} / \mathrm{nm}^{2} / \mathrm{s}$. The appearance of new particles can either be attributed to the nucleation of new $\mathrm{CoCO}_{3}$ nanoparticles or to the growth of particles present at the beginning of the observation which was below the detection limit. In our experiments, the detection limit is estimated, following ref 26, to be $40 \mathrm{~nm}$ for $\mathrm{CoCO}_{3}$ nanoparticles in a $500 \mathrm{~nm}$ water layer imaged with an electron flux of $30 \mathrm{e}^{-} / \mathrm{nm}^{2} / \mathrm{s}$.

Post analysis of the image series showed that alongside the nanoparticles, there was also a thin film of mineral deposited on the chip surface but only in the observation area (Figure 2). 

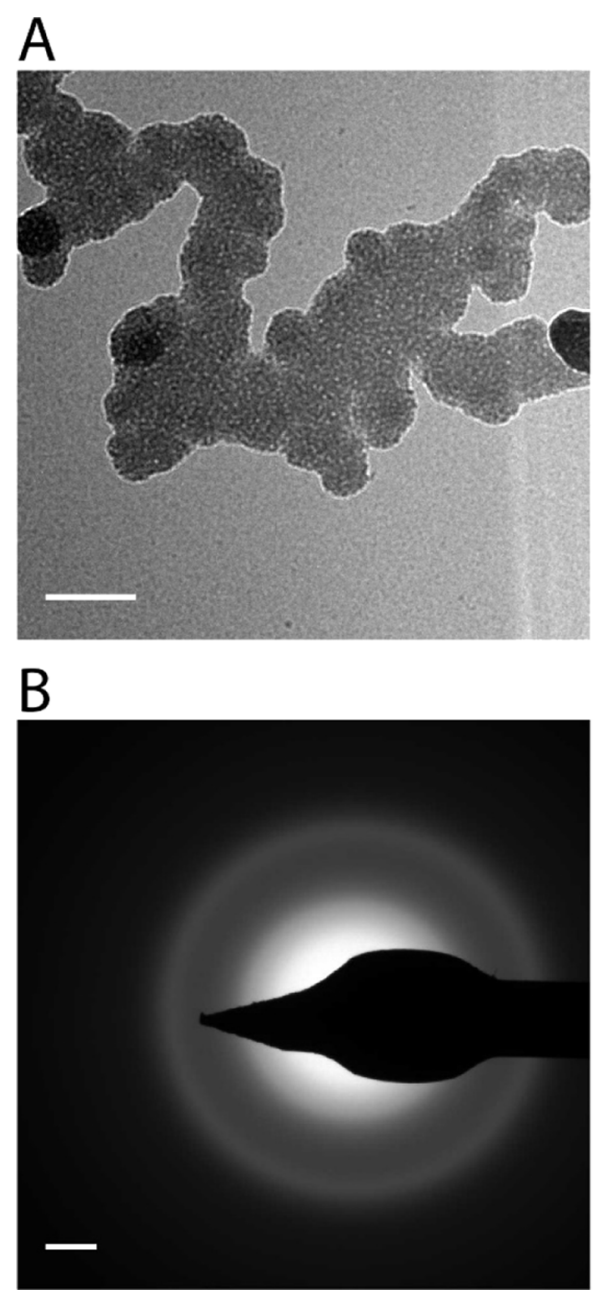

C

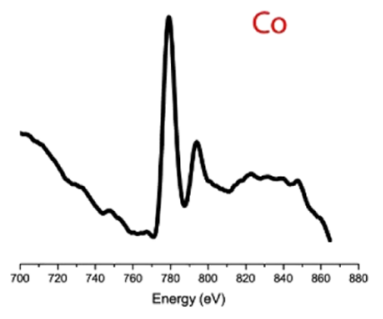

D
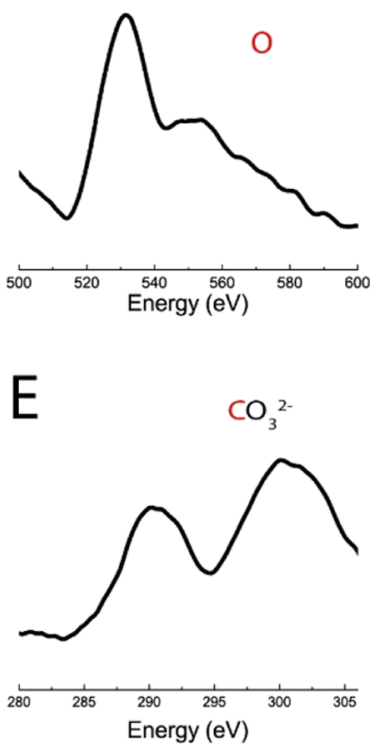

Figure 2. Post analysis of the formed nanostructures. (a) BF TEM image at the edge of the illumination area. It can be seen clearly that materials were deposited on the imaging area. Scale bar is $100 \mathrm{~nm}$. (b) Electron diffraction pattern of the nanoparticles formed in (a), indicating that only amorphous particles were formed. Scale bar $21 / \mathrm{nm}$. (c-e) EELS results indicate the certain components found on the particles. The peak at 782 $\mathrm{eV}$ matches the $\mathrm{L}_{3}$ edge of $\mathrm{Co}^{2+}(\mathrm{c})$, and the $\mathrm{K}$ edge of oxygen $(540 \mathrm{eV})(\mathrm{d})$ and carbon $(290 \mathrm{eV})(\mathrm{e})$ matches the $\mathrm{EELS}$ spectra of $\mathrm{CO}_{3}{ }^{2-} \cdot{ }^{27,28}$

The thickness of this thin film increased when using a higher electron flux (see Supporting Information SI2 post analysis Figure S2, from $2-3 \mathrm{~nm}$ at $7.8 \mathrm{e}^{-} / \mathrm{nm}^{2} / \mathrm{s}$ to $8-9 \mathrm{~nm}$ at $30 \mathrm{e}^{-} /$ $\mathrm{nm}^{2} / \mathrm{s}$ ). Energy-dispersive X-ray spectroscopy (EDX) showed that these thin films have the same composition as the particles, revealing that they were also composed of amorphous $\mathrm{CoCO}_{3}$ (Figure 2a, electron diffraction, Supporting Information SI2 post analysis Figure S2).

Data on the growth kinetics of the amorphous $\mathrm{CoCO}_{3}$ nanoparticles were extracted from the time-lapse image series recorded from both the $\mathrm{BF}$ and $\mathrm{ADF}$ detector. The BF STEM signal (Figure 3a), which has a higher signal-to-noise ratio, was used for image segmentation (Supporting Information SI3 image analysis) to produce an accurate time-dependent mask (Figure $3 b, c$ ) of the nanoparticles, while the $\mathrm{ADF}$ intensity, which is proportional to the thickness of the particles, was used to monitor their thickness development as a function of time and electron flux. The summed ADF STEM intensities in the masked area were used to derive $\mathrm{CoCO}_{3}$ volume development (Figure 3d). From the intensity plots, it can be seen that due to the interaction between the particle and substrate, half spheres instead of full spheres are formed.

From the abovementioned procedure, the volume ratio development $\left(V_{t} / V_{0}\right)$ was calculated for different electron fluxes (Figure 3e), which shows that the $\mathrm{CoCO}_{3}$ particle volume grows linearly with time, indicating that a constant amount of material is deposited on the particles (constant volume growth rate) and the $\mathrm{Co}^{2+}$ and $\mathrm{CO}_{3}{ }^{2-}$ ions were not depleted during the observation. Therefore, we attribute this linear volume growth to a change in the chemical environment caused by the local illumination during STEM imaging. In line with this, the volume growth rate increased linearly with the increase of the electron flux (Figure 3f). Furthermore, in the STEM mode, the sample is only illuminated in a limited area (from $3 \mu \mathrm{m} \times 3 \mu \mathrm{m}$ to $8.5 \mu \mathrm{m} \times 8.5 \mu \mathrm{m}$ in these experiments), which is much smaller than the total area of the SiN chip $(2000 \mu \mathrm{m} \times 2200 \mu \mathrm{m})$. The fact that only a small area is imaged prevents depletion of $\mathrm{Co}^{2+}$ and $\mathrm{CO}_{3}{ }^{2-}$ ions during observation.

Analysis of the Electron Beam Effects. To understand how the interaction of the solution with the electron beam increases the supersaturation, a control experiment was performed with the liquid cell only filled with $120 \mathrm{mM}$ Co $\left(\mathrm{NO}_{3}\right)_{2}$ solution and illuminated in the TEM mode (a previous study has shown that chemical processes resulting from solution-e-beam interactions are independent of the imaging mode). ${ }^{16}$ In this control experiment, we observed the formation and growth of nanoparticles (see Supporting 
A

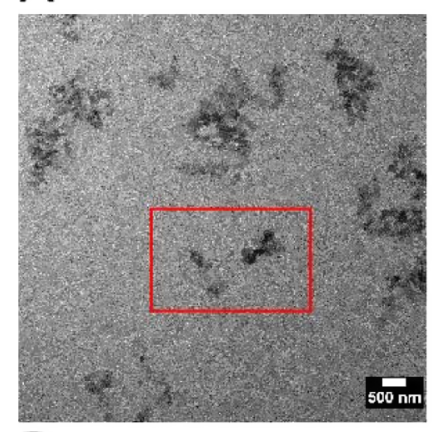

D

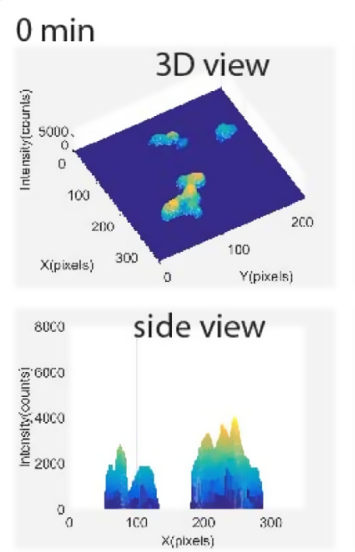

$\mathrm{E}$

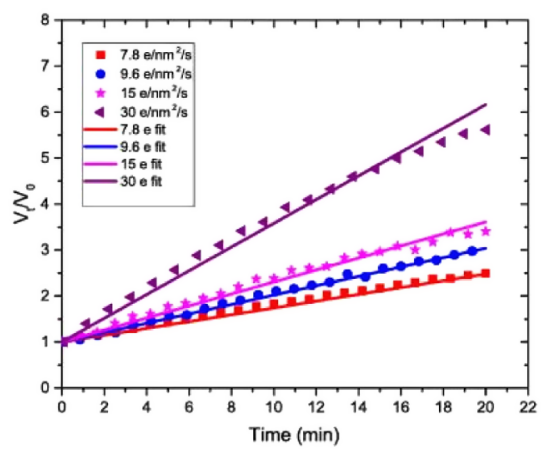

B

$7 \mathrm{~min}$
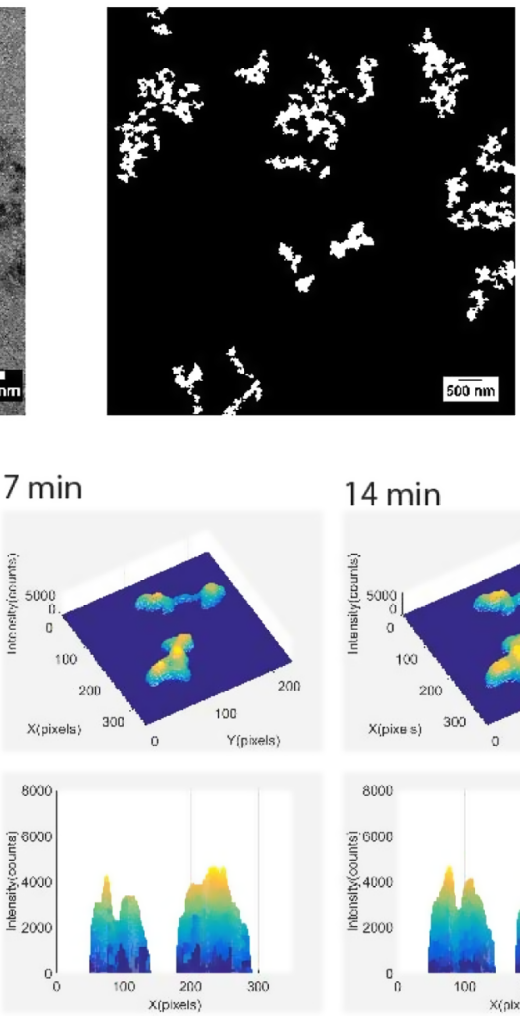

$14 \min$

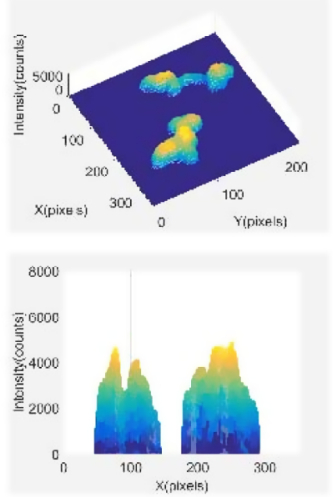

F

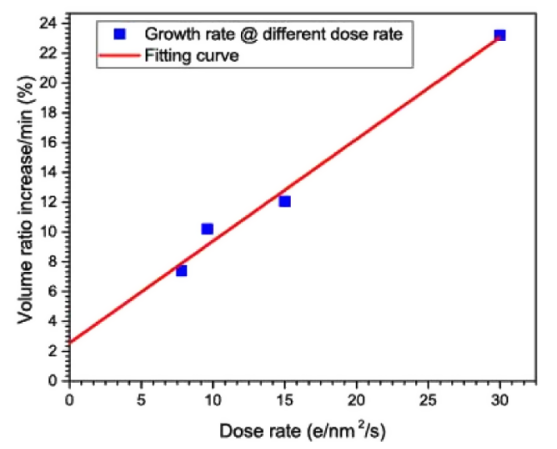

Figure 3. Analysis of image series and volume development of the nanoparticles. (a) BF STEM image of $\mathrm{CoCO}_{3}$ at electron flux of 7.8 e/nm ${ }^{2} / \mathrm{s}$ at $t$ $=0 \mathrm{~min}$. The red rectangle indicates the cropped area from which the data is shown in $(\mathrm{d})$. (b,c) Binary image mask derived by thresholding (a). The particle mask (b) or the background mask (c) are with intensity "1" in bright regions. (d) 3D intensity plot of the particles from (c), indicating the nanoparticle volume development in time. (e) Volume development at different electron fluxes. (f) Linear fit of the volume ratio growth rate at different electron fluxes. A movie of (d) is provided in Video S2.

Information SI4 control experiment, Figure S4) for which postexperimental EDX showed that they contained Co and $\mathrm{O}$, indicating that they consisted of $\mathrm{CoO}$ and/or $\mathrm{Co}(\mathrm{OH})_{2}$. According to the Pourbaix diagram of the $\mathrm{Co}-$ water system, $\mathrm{CoO}$ and $\mathrm{Co}(\mathrm{OH})_{2}$ only precipitate at a $\mathrm{pH}$ higher than 7 (Supporting Information Figure S5), implying that the $\mathrm{pH}$ of the solution increases under electron radiation when $\mathrm{Co}^{2+}$ ions are present and that the electrons promoted growth because of a local increase of the $\mathrm{pH}$ in the illumination area. This is similar to what was reported for solutions containing $\mathrm{Ce}^{4+}$ ions where the $\mathrm{pH}$ of the solution also increases because of interactions with the electron beam. ${ }^{17}$ It is important to note that this contrasts the situation in pure water where, among the formation of many radiolysis products, the formation of $\mathrm{H}_{3} \mathrm{O}^{+}$ is dominant, and a drop in the local $\mathrm{pH}$ of the solution is predicated upon electron irradiation. ${ }^{16}$

For the full reaction, in parallel with reducing the solubility of the cobalt ions, the locally increased $\mathrm{pH}$ in the $\mathrm{CoCO}_{3}$ growth experiments will drive the conversion of $\mathrm{HCO}_{3}{ }^{2-}$ into $\mathrm{CO}_{3}{ }^{2-}$. The increased $\mathrm{CO}_{3}{ }^{2-}$ concentration leads to a higher supersaturation, in turn, driving the precipitation of amorphous $\mathrm{CoCO}_{3}$.

The above findings were further supported by experiments performed at a constant electron flux $\left(30 \mathrm{e}^{-} / \mathrm{nm}^{2} / \mathrm{s}\right)$ but with a different initial reactant concentration. These experiments showed that with the increasing $\mathrm{Co}^{2+}$ concentration, the volume growth rate of $\mathrm{CoCO}_{3}$ decreased (Figure 4a). In contrast, when the $\mathrm{CO}_{3}{ }^{2-}$ concentration was increased from 15 to $30 \mathrm{mM}$, the volume ratio development was nearly 
A

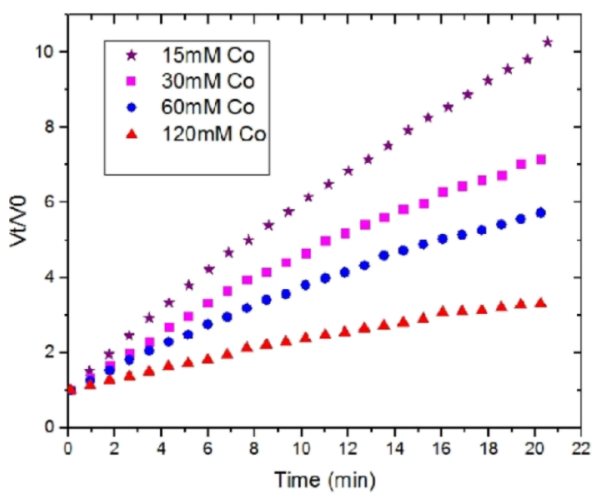

C

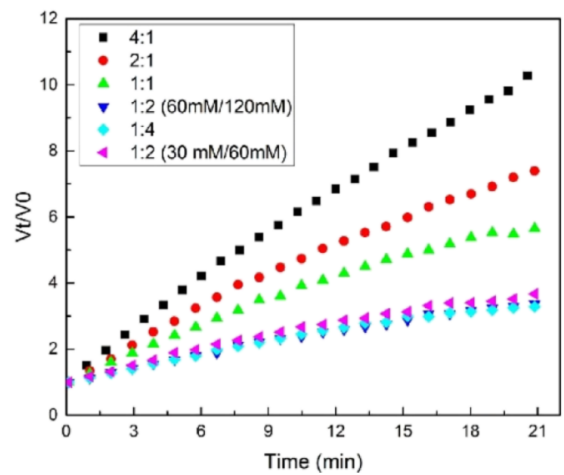

B

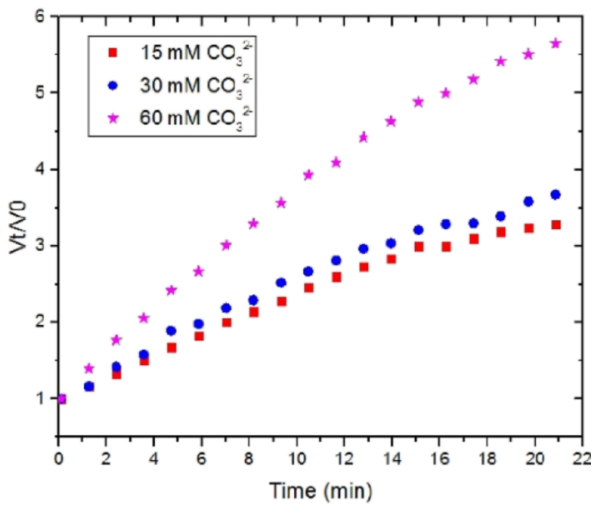

D

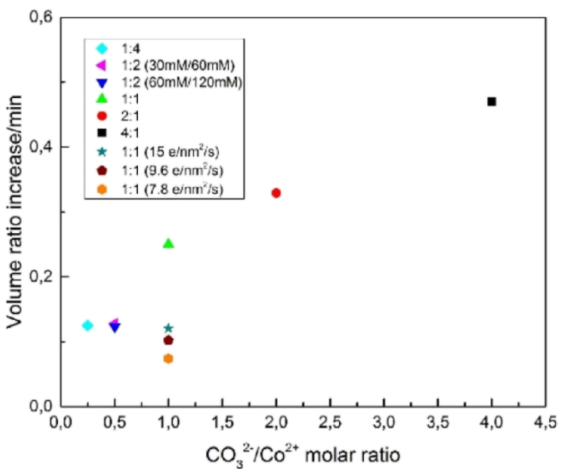

Figure 4. Volume ratio increases at different component concentration. The electron flux was set at $30 \mathrm{e}^{-} / \mathrm{nm}^{2} / \mathrm{s}$ if not stated otherwise. (a) Volume ratio increases at a fixed $\mathrm{CO}_{3}{ }^{2-}$ concentration of $60 \mathrm{mM}$ and varying $\mathrm{Co}^{2+}$ concentration. (b) Volume ratio increases at a fixed $\mathrm{Co}^{2+}$ concentration of $60 \mathrm{mM}$ and a varying $\mathrm{CO}_{3}{ }^{2-}$ concentration. (c) Volume ratio increases at varying $\mathrm{CO}_{3}{ }^{2-} / \mathrm{Co}^{2+}$ molar ratios. (d) Volume ratio increases at varying $\mathrm{CO}_{3}{ }^{2-} / \mathrm{Co}^{2+}$ molar ratios and different electron fluxes.

unchanged, while upon increasing the initial $\mathrm{CO}_{3}{ }^{2-}$ concentration to $60 \mathrm{mM}$, a significant increase in the volume development was observed (Figure $4 b$ ). Significantly, further analysis of these data revealed that the volume ratio growth rate was only dependent on the initial $\left[\mathrm{CO}_{3}{ }^{2-}\right] /[\mathrm{Co}]$ ratio in solution (Figure $4 \mathrm{c}$ ). When the growth rate is invariant at molar ratios of $\left[\mathrm{CO}_{3}{ }^{2-}\right] /\left[\mathrm{Co}^{2+}\right]<1$, the volume growth rate increased with the $\left[\mathrm{CO}_{3}{ }^{2-}\right] /[\mathrm{Co}]$ ratio for values of $\left[\mathrm{CO}_{3}{ }^{2-}\right] /$ $\left[\mathrm{Co}^{2-}\right] \geq 1$.

Here, it is important to consider the $\mathrm{pH}$ dependence of the chemical speciation in the carbonic acid/bicarbonate/carbonate system. ${ }^{29,30}$ As significant concentrations of $\mathrm{CO}_{3}{ }^{2-}$ are only present above a $\mathrm{pH}$ of 8.3 at ambient temperature, the formation of $\mathrm{CoCO}_{3}$ can only occur above this critical value. Ex situ experiments (Supporting Information Figure S7) show that the higher $\left[\mathrm{CO}_{3}{ }^{2-}\right] /\left[\mathrm{Co}^{2+}\right]$ values are associated with a higher starting $\mathrm{pH}$, also relating the observed higher volume ratio growth rate to a higher starting $\mathrm{pH}$ value. For the concentration control experiments, the electron flux was set at the same value $\left(30 \mathrm{e}^{-} / \mathrm{nm}^{2} / \mathrm{s}\right)$. Thus, the solution with a higher starting $\mathrm{pH}$ should end up with a higher equilibrium $\mathrm{pH}$ after electron radiation, creating a higher $\mathrm{CO}_{3}{ }^{2-}$ concentration and volume growth rate.

Volume Growth Rate in the Native State. The volume growth rate in the native state can be derived from the growth rates at different electron fluxes by extrapolating to zero electron flux (Figure 3f). To compare the extrapolation results with the actual growth rate without electron beam effects, we analyzed the particle growth in the vicinity of the imaging area
(Figure S6). This shows (Figure S6a,b) that the size of particles surrounding the imaging area also increases after imaging. Performing the same volume analysis on particles at different distances from the imaging area (Figure S6c) demonstrates that the volume growth rate decreases with an increasing distance from the imaging area (Figure S6d). When particles are $3 \mu \mathrm{m}$ or more away from the imaging area, the growth rate is comparable to the extrapolated zero electron dose growth rate (Figure S6d). This is in line with a previous report stating that most of the species which are generated by the electron beam-water interaction cannot diffuse further than $2-3 \mu \mathrm{m} .{ }^{16}$ Thus, the growth of the nanoparticles $3 \mu \mathrm{m}$ away from the imaging area is not influenced by the e-beam. Therefore, we conclude that the extrapolation of the growth rate to zero electron flux shows the native growth rate, unaffected by the electron beam.

Growth Mechanism of Amorphous $\mathrm{CoCO}_{3}$. The observed linear volume growth of $\mathrm{CoCO}_{3}$ in time is seemingly in violation of classical considerations of crystal growth occurring through the attachment and detachment of monomers in solution, described by ${ }^{31}$

$$
v=\Omega \beta\left(C-C_{\mathrm{e}}\right)
$$

where $v$ is the growth rate (length/time, i.e., $\mathrm{nm} / \mathrm{s}$ ), $\Omega$ is the volume of the monomer, $\beta$ is the kinetic factor, $C$ is the monomer concentration, and $C_{\mathrm{e}}$ is the monomer concentration at equilibrium. This predicts that the radius of the particles grows linearly with time, leading to a nonlinear volume increase (i.e., volume growth rate) that scales with the square 
of the radius. This indicates that the observed growth of the $\mathrm{CoCO}_{3}$ particles is not governed by the attachment and detachment of ions in a supersaturated solution.

The question then arises as to why the volume of the amorphous $\mathrm{CoCO}_{3}$ particles grows at a constant rate and what is actually driving the growth. The classical nucleation theory predicts that the nucleation rate (number of formed nuclei/ volume/time) can be described as ${ }^{31,32}$

$$
J_{\mathrm{n}}=A \exp \left(-B \alpha^{3} / \sigma^{2}\right)
$$

where $A$ is a pre-exponential factor, $B$ is the factor related to the temperature and volume of the material, $\alpha$ is the interfacial energy, and $\sigma$ is the supersaturation of the solution. This implies that at a given supersaturation, the nucleation rate is constant; hence, the total volume of formed nuclei increases linearly with time, similar to the linear volume growth rate observed in our experiments. From this, it follows that in our experiments, volume creation is driven by nucleation rather than by ion-by-ion growth. The nucleation of small building units, which we term primary particles, could form the source of $\mathrm{CoCO}_{3}$ from which the amorphous particles are formed. Therefore, we hypothesize that the growth of amorphous $\mathrm{CoCO}_{3}$ most probably occurs through the aggregation of $\mathrm{CoCO}_{3}$ primary particles, which are individually below the detection limit of LPSTEM.

To test our hypothesis, we investigated the presence of primary particles by performing cryoTEM (Figure 5) and DLS
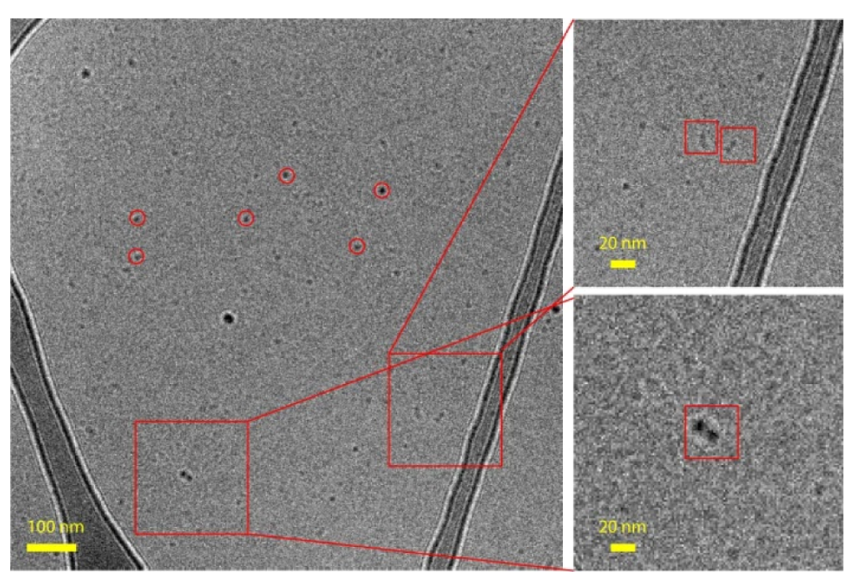

Figure 5. CryoTEM image of the $\mathrm{Co}\left(\mathrm{NO}_{3}\right)_{2}$ and $\left(\mathrm{NH}_{4}\right)_{2} \mathrm{CO}_{3}$ solution mixture after centrifugation. The red circle indicates the typical $\sim 10 \mathrm{~nm}$ nanoparticles in solution. The red squares highlight the region of the $\sim 10 \mathrm{~nm}$ particle merging.

(Figure S8) on the reaction solution after centrifugation. CryoTEM reveals that there are $\sim 10 \mathrm{~nm}$ nanoparticles present in solution. CryoTEM also shows that some of these particles were merging to form larger structures (Figure 5, magnified regions). In addition, DLS indicated the existence of particles with an average diameter of $15 \mathrm{~nm}$ (Figure S8), which were increasing in size during the DLS measurements. Thus, CryoTEM and DLS suggest that the growth of amorphous $\mathrm{CoCO}_{3}$ particles indeed can occur through nucleationaggregation as was also found for the formation of $\mathrm{CaCO}_{3} \cdot{ }^{9,10}$ Because the size of the primary particles is much smaller than the aggregates formed before electron illumination, the contact area between the primary nanoparticles and the $\mathrm{SiN}$ window is quite small, leading to a much weaker van der Waals force between the primary nanoparticles and the substrate. ${ }^{24,25}$ Thus, the primary nanoparticles can move freely in the solution and agglomerate into larger amorphous structures through Brownian motion as reported in a $\mathrm{CaCO}_{3}$ system. ${ }^{9,10}$ Moreover, because the electron beam was focused on the bottom window, this imaging area becomes charged, causing electrostatic attraction to the primary particles and resulting in deposition of a thin film as shown in Figure 2A. The effect of particle substrate interaction on growth kinetics is that a half sphere instead of a full sphere is formed as shown in the intensity map in Figure 3D. In Figure 6, we summarize our
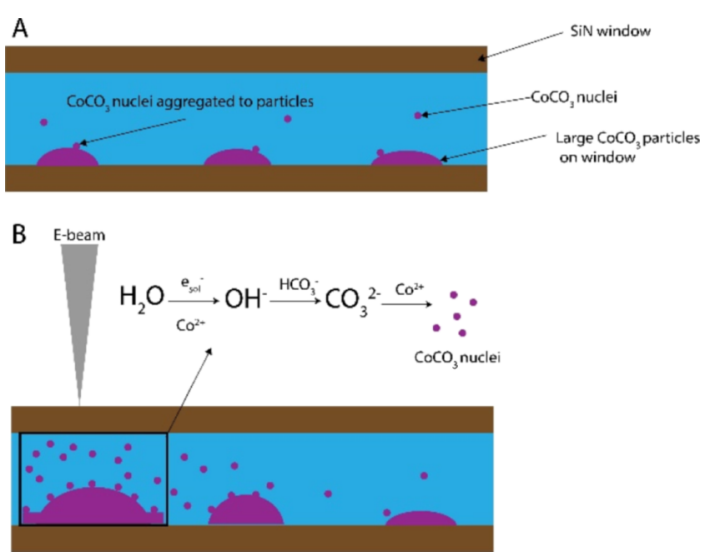

Figure 6. Proposed reaction mechanism before (a) and after electron illumination. The electron beam generates $\mathrm{OH}^{-}$ions and therefore increases the $\mathrm{pH}$. Subsequently, the $\mathrm{HCO}_{3}{ }^{-}$ions are transferred to $\mathrm{CO}_{3}{ }^{2-}$ ions, increasing the supersaturation. Thus, more $\mathrm{CoCO}_{3}$ nuclei were formed and aggregate on either the $\mathrm{SiN}$ window or the particles. This process can also influence the particle growth next to the imaging area. The growth of particles that are $3 \mu \mathrm{m}$ away is not influenced.

findings and propose a mechanism for amorphous $\mathrm{CoCO}_{3}$ particle formation and growth. After mixing the reactants, large $\mathrm{CoCO}_{3}$ nanoparticles (around $50 \mathrm{~nm}$ as a single particles) were formed on the $\mathrm{SiN}$ window and $\sim 10 \mathrm{~nm}$ primary nanoparticles are present in solution. These primary particles deposit on the surface of the larger particles and increase their volume. When the suspension is illuminated by the electron beam, the $\mathrm{pH}$ of the solution increases and therefore drives the conversion of $\mathrm{HCO}_{3}{ }^{-}$into $\mathrm{CO}_{3}{ }^{2-}$, increasing the supersaturation locally, increasing the nucleation rate of the $\mathrm{CoCO}_{3}$ primary particles. It is this constant generation of primary particles that is responsible for the observed linear growth rate of the amorphous $\mathrm{CoCO}_{3}$.

\section{CONCLUSIONS}

We have demonstrated that by LPSTEM, the nanoscale growth dynamics of amorphous $\mathrm{CoCO}_{3}$ can be imaged. Furthermore, by careful dose control during imaging and by detailed analysis of the image series, combining $\mathrm{BF}$ and $\mathrm{ADF}$ signals, we were able to quantify the real-time growth kinetics in solution. Although the electron beam-solution interaction cannot be avoided, we can obtain the actual growth kinetics by measuring the volume ratio growth rate at different electron fluxes and then extrapolating the growth rate to zero electron flux. This approach is general and can be applied to study other (mineralization) systems, tracking their growth in 3D.

From our experimental observations, we conclude that the increased growth rate of amorphous $\mathrm{CoCO}_{3}$ is driven by an 
electron beam-induced local $\mathrm{pH}$ increase to above $\mathrm{pH}=8.3$, which in the viewing area leads to a locally increased supersaturation. Around this area, the concentration of different reactants is constant and forms a feedstock for the reaction. The solution supersaturation induces the nucleation of $\mathrm{CoCO}_{3}$ forming $\sim 10 \mathrm{~nm} \mathrm{CoCO}_{3}$ primary particles, which then aggregate on the existing particles that were formed upon mixing of the precursor solutions.

Our observations, for the first time, provide evidence that an amorphous phase is formed through primary particle assembly. Besides quantifying growth kinetics, we believe that these insights will contribute to the control of the size of $\mathrm{CoCO}_{3}$ nanoparticles (i.e., through titration), which is an important intermediate for cobalt catalysts employed, for example, in Fischer-Tropsch synthesis.

\section{MATERIALS AND METHODS}

In situ imaging was performed using the DENSsolutions Ocean type in situ holder which holds two $2.2 \times 2.0 \times 0.2 \mathrm{~mm}$ $\mathrm{SiN} / \mathrm{Si}$ microchips with a liquid layer of $400-1000 \mathrm{~nm}$ in between. The microchips consist of $\mathrm{Si}$ supports with a $200 \times$ $18 \mu \mathrm{m}$ window made from a $50 \mathrm{~nm}$ amorphous $\mathrm{Si}_{x} \mathrm{~N}_{y}$ membrane. The two chips were assembled orthogonally forming a viewing area of $18 \mu \mathrm{m} \times 18 \mu \mathrm{m}$. To minimize the thickness of the liquid layer, no additional spacers were used. The chips were plasma-cleaned (Fischione model 1020 plasma cleaner) for $1 \mathrm{~min}$ with a 50:50 (v/v) $\mathrm{Ar} / \mathrm{O}_{2}$ plasma at a pressure of $150 \mathrm{mTorr}$. In all the experiments, Milli-Q water was used as the solvent.

Growth of the $\mathrm{CoCO}_{3}$ nanoparticles as initiated by mixing a drop of aqueous $\left(\mathrm{NH}_{4}\right)_{2} \mathrm{CO}_{3}$ solution $(500 \mathrm{~nL})$ and a drop of $\mathrm{Co}\left(\mathrm{NO}_{3}\right)_{2}$ solution $(500 \mathrm{~nL})$ to the bottom chip. To initiate the reaction in the LP STEM viewing area, different approaches were tested including the flowing-in of reagents. However, mixing the solutions on the bottom chip was found to be the most reproducible and reliable method for this reaction.

Amorphous $\mathrm{CoCO}_{3}$ is a very stable phase, of which the transition from amorphous to crystalline requires days of aging at ambient temperature or heating the solution to $45-60{ }^{\circ} \mathrm{C}$. ${ }^{18}$ The time we spent for the experiment, typically $30 \mathrm{~min}$, is not enough for the crystallization to take place and, therefore, no crystallization of amorphous cobalt carbonate was observed in all of our experiments.

TEM observations were performed on a monochromated and probe-corrected FEI Titan which was operated in the STEM mode at $300 \mathrm{kV}$ with simultaneous use of the BF and the ADF STEM detectors (collection angle 43.86-220 mrad). The electron flux was first calibrated based on the previous published procedures, ${ }^{33}$ and imaging was performed at a set of predetermined values (between 7.8 and $30 \mathrm{e}^{-} / \mathrm{nm}^{2} / \mathrm{s}$ ). Observation of the nanoparticle growth only takes place at the edge or the corner of the viewing window, where the liquid layer thickness is $300-400 \mathrm{~nm}$. For our in situ experiments, the use of the STEM imaging mode is highly beneficial because this reduces the illuminated or imaged area $(3 \mu \mathrm{m} \times 3 \mu \mathrm{m}$ to $8.5 \mu \mathrm{m} \times 8.5 \mu \mathrm{m})$ to a fraction of the total chip area $(2200 \mu \mathrm{m}$ $\times 2000 \mu \mathrm{m}$ ), determining the volume of the liquid reservoir. Thus, only $1 / 60000$ of the liquid reservoir of the solution is interacting with the electron beam, leaving the concentration of the $\mathrm{Co}^{2+}$ ions and $\mathrm{CO}_{3}{ }^{2-}$ ions almost unchanged during the performed in situ experiments.
For the control experiments without $\left(\mathrm{NH}_{4}\right)_{2} \mathrm{CO}_{3}$ solution being present, an FEI Tecnai transmission electron microscope was used, operated at $200 \mathrm{kV}$ in the TEM mode. The $120 \mathrm{mM}$ $\mathrm{Co}^{2+}$ solution was illuminated at an electron flux of $50 \mathrm{e}^{-} /$ $\mathrm{nm}^{2} / \mathrm{s}$.

Analysis of the time-resolved image series was performed in Matlab which is discussed in detail in the Supporting Information section SI3.

After the reaction (20-25 $\mathrm{min}$ in a TEM column), the two $\mathrm{SiN} / \mathrm{Si}$ chips were taken out from the in situ transmission electron microscope holder and washed with Milli-Q water. They were subsequently studied individually in conventional TEM and SEM by EELS, electron diffraction, and EDX.

\section{ASSOCIATED CONTENT}

\section{Supporting Information}

The Supporting Information is available free of charge on the ACS Publications website at DOI: 10.1021/acs.jpcc.9b06078.

Ex situ experiments, post analysis of the particles, and image analysis (PDF)

Example of real-time in situ TEM movies and 3D volume growth (ZIP)

\section{AUTHOR INFORMATION}

\section{Corresponding Authors}

*E-mail: nico.sommerdijk@radboudumc.nl (N.A.J.M.).

*E-mail: Browning@liverpool.ac.uk (N.D.B.).

*E-mail: H.Friedrich@tue.nl (H.F.).

ORCID

B. L. Mehdi: 0000-0002-8281-9524

J. P. Patterson: 0000-0002-1975-1854

N. A. J. M. Sommerdijk: 0000-0002-8956-195X

H. Friedrich: 0000-0003-4582-0064

\section{Present Addresses}

${ }^{\perp}$ Imaging Center at Liverpool (ICaL), School of Engineering \&amp; School of Physical Sciences, University of Liverpool, 506 Brodie Tower, Liverpool, L69 3GQ, UK.

\#Dept. of Biochemistry Radboud Institute of Molecular Life Sciences Radboud University Medical Center 6525 GA Nijmegen.

\section{Author Contributions}

H.S. performed the STEM experiments and all data analysis. B.L.M. assisted in the STEM experimental design and performed EELS and EDX observation. J.P.P. assisted in STEM observation, conceived the idea of the beam-blank data experiments, and assisted in image analysis. All the authors contributed in revising the manuscript. All the authors have given approval to the final version of the manuscript.

\section{Funding}

This work is funded by Shell Global Solutions and the Netherlands Association of Scientific Research (NWO) through the CHIPP program.

\section{Notes}

The authors declare no competing financial interest.

\section{ACKNOWLEDGMENTS}

The authors would like to thank Karthikeyan Gnanasekaran for helpful discussion on the mean free path calculations and Hanglong $\mathrm{Wu}$ for assistance with image analysis. 


\section{REFERENCES}

(1) De Yoreo, J. J.; et al. Crystallization by Particle Attachment in Synthetic, Biogenic, and Geologic Environments. Science 2015, 349, aaa6760.

(2) Xu, Y.; Tijssen, K. C. H.; Bomans, P. H. H.; Akiva, A.; Friedrich, H.; Kentgens, A. P.; Sommerdijk, N. A. J. M. Microscopic Structure of the Polymer-Induced Liquid Precursor for Calcium Carbonate. Nat. Commun. 2018, 9, 2582.

(3) Nielsen, M. H.; Aloni, S.; De Yoreo, J. J. In Situ Tem Imaging of Caco3 Nucleation Reveals Coexistence of Direct and Indirect Pathways. Science 2014, 345, 1158.

(4) Politi, Y.; Arad, T.; Klein, E.; Weiner, S.; Addadi, L. Sea Urchin Spine Calcite Forms Via a Transient Amorphous Calcium Carbonate Phase. Science 2004, 306, 1161-1164.

(5) Habraken, W. J. E. M.; et al. Ion-Association Complexes Unite Classical and Non-Classical Theories for the Biomimetic Nucleation of Calcium Phosphate. Nat. Commun. 2013, 4, 1507.

(6) Posner, A. S.; Betts, F. Synthetic Amorphous Calcium Phosphate and Its Relation to Bone Mineral Structure. Acc. Chem. Res. 1975, 8, 273-281.

(7) Dey, A.; Bomans, P. H. H.; Müller, F. A.; Will, J.; Frederik, P. M.; de With, G.; Sommerdijk, N. A. J. M. The Role of Prenucleation Clusters in Surface-Induced Calcium Phosphate Crystallization. Nat. Mater. 2010, 9, 1010.

(8) Baumgartner, J.; Dey, A.; Bomans, P. H. H.; Le Coadou, C.; Fratzl, P.; Sommerdijk, N. A. J. M.; Faivre, D. Nucleation and Growth of Magnetite from Solution. Nat. Mater. 2013, 12, 310.

(9) Pouget, E. M.; Bomans, P. H. H.; Dey, A.; Frederik, P. M.; de With, G.; Sommerdijk, N. A. J. M. The Development of Morphology and Structure in Hexagonal Vaterite. J. Am. Chem. Soc. 2010, 132, $11560-11565$.

(10) Pouget, E. M.; Bomans, P. H. H.; Goos, J. A. C. M.; Frederik, P. M.; de With, G.; Sommerdijk, N. A. J. M. The Initial Stages of Template-Controlled Caco3 Formation Revealed by Cryo-Tem. Science 2009, 323, 1455-1458.

(11) Li, D.; Nielsen, M. H.; Lee, J. R. I.; Frandsen, C.; Banfield, J. F.; De Yoreo, J. J. Direction-Specific Interactions Control Crystal Growth by Oriented Attachment. Science 2012, 336, 1014-1018.

(12) Liao, H.-G.; Cui, L.; Whitelam, S.; Zheng, H. Real-Time Imaging of Pt3Fe Nanorod Growth in Solution. Science 2012, 336, 1011-1014.

(13) Ross, F. M. Opportunities and Challenges in Liquid Cell Electron Microscopy. Science 2015, 350, aaa9886.

(14) De Yoreo, J. J.; Sommerdijk, N. A. J. M. Investigating Materials Formation with Liquid-Phase and Cryogenic Tem. Nat. Rev. Mater. 2016, 1, 16035 .

(15) Smeets, P. J. M.; Cho, K. R.; Kempen, R. G. E.; Sommerdijk, N. A. J. M.; De Yoreo, J. J. Calcium Carbonate Nucleation Driven by Ion Binding in a Biomimetic Matrix Revealed by in Situ Electron Microscopy. Nat. Mater. 2015, 14, 394-399.

(16) Schneider, N. M.; Norton, M. M.; Mendel, B. J.; Grogan, J. M.; Ross, F. M.; Bau, H. H. Electron-Water Interactions and Implications for Liquid Cell Electron Microscopy. J. Phys. Chem. C 2014, 118, 22373-22382.

(17) Abellan, P.; Moser, T. H.; Lucas, I. T.; Grate, J. W.; Evans, J. E.; Browning, N. D. The formation of cerium(iii) hydroxide nanoparticles by a radiation mediated increase in local pH. RSC Adv. 2017, 7, 3831-3837.

(18) González-López, J.; Fernández-González, Á.; Jiménez, A. Crystallization of Nanostructured Cobalt Hydroxide Carbonate at Ambient Conditions: A Key Precursor of Co3o4. Mineral. Mag. 2016, 80, 995-1011.

(19) Bezemer, G.; Radstake, P.; Koot, V.; Vandillen, A.; Geus, J.; Dejong, K. Preparation of Fischer-Tropsch Cobalt Catalysts Supported on Carbon Nanofibers and Silica Using Homogeneous Deposition-Precipitation. J. Catal. 2006, 237, 291-302.

(20) Bezemer, G. L.; Bitter, J. H.; Kuipers, H. P. C. E.; Oosterbeek, H.; Holewijn, J. E.; Xu, X.; Kapteijn, F.; van Dillen, A. J.; De Jong, K. P. Cobalt Particle Size Effects in the Fischer-Tropsch Reaction
Studied with Carbon Nanofiber Supported Catalysts. J. Am. Chem. Soc. 2006, 128, 3956-3964.

(21) Bezemer, G. L.; Falke, U.; van Dillen, A. J.; de Jong, K. P. Cobalt on Carbon Nanofiber Catalysts: Auspicious System for Study of Manganese Promotion in Fischer-Tropsch Catalysis. Chem. Commun. 2005, 731-733.

(22) Eggenhuisen, T. M.; Munnik, P.; Talsma, H.; De Jongh, P. E.; De Jong, K. P. Freeze-Drying for Controlled Nanoparticle Distribution in Co/Sio 2 Fischer-Tropsch Catalysts. J. Catal. 2013, 297, 306-313.

(23) Pennycook, S. J.; Nellist, P. D. Scanning Transmission Electron Microscopy: Imaging and Analysis; Springer: New York, 2011.

(24) You, S.; Wan, M. P. Mathematical Models for the Van Der Waals Force and Capillary Force between a Rough Particle and Surface. Langmuir 2013, 29, 9104-9117.

(25) Joo, S.; Baldwin, D. F. Adhesion Mechanisms of Nanoparticle Silver to Substrate Materials: Identification. Nanotechnology 2009, 21, 055204.

(26) de Jonge, N. Theory of the Spatial Resolution of (Scanning) Transmission Electron Microscopy in Liquid Water or Ice Layers. Ultramicroscopy 2018, 187, 113-125.

(27) Arnold, M.; Xu, Q.; Tichelaar, F. D.; Feldhoff, A. Local Charge Disproportion in a High-Performance Perovskite. Chem. Mater. 2009, $21,635-640$

(28) Kłosowski, M. M.; Friederichs, R. J.; Nichol, R.; Antolin, N.; Carzaniga, R.; Windl, W.; Best, S. M.; Shefelbine, S. J.; McComb, D. W.; Porter, A. E. Probing Carbonate in Bone Forming Minerals on the Nanometre Scale. Acta Biomater. 2015, 20, 129-139.

(29) Tran, H. V.; Tran, L. D.; Vu, H. D.; Thai, H. Facile Surface Modification of Nanoprecipitated Calcium Carbonate by Adsorption of Sodium Stearate in Aqueous Solution. Colloids Surf., A 2010, 366, 95-103.

(30) Ihli, J.; Bots, P.; Kulak, A.; Benning, L. G.; Meldrum, F. C. Elucidating Mechanisms of Diffusion-Based Calcium Carbonate Synthesis Leads to Controlled Mesocrystal Formation. Adv. Funct. Mater. 2013, 23, 1965-1973.

(31) De Yoreo, J. J.; Vekilov, P. G. Principles of Crystal Nucleation and Growth. Rev. Mineral. Geochem. 2003, 54, 57-93.

(32) Mullin, J. W. Crystallization; Elsevier, 2001.

(33) Abellan, P.; Woehl, T. J.; Parent, L. R.; Browning, N. D.; Evans, J. E.; Arslan, I. Factors Influencing Quantitative Liquid (Scanning) Transmission Electron Microscopy. Chem. Commun. 2014, 50, 48734880. 